\title{
Binding and lethal effect of complement from Oncorhynchus mykiss on Gyrodactylus derjavini (Platyhelminthes: Monogenea)
}

\author{
K. Buchmann* \\ Department of Veterinary Microbiology, Section of Fish Diseases, Royal Veterinary and Agricultural University, \\ 13 Bülowsvej, DK-1870 Frederiksberg C, Denmark
}

\begin{abstract}
A lethal effect of rainbow trout Oncorhynchus mykiss plasma containing intact complement factors on Gyrodactylus derjavini was demonstrated. It was associated with binding of complement factor $\mathrm{C} 3$ to certain carbohydrate-rich parasite structures. Parasites were exposed in vitro to plasma from rainbow trout. Untreated plasma from infected and uninfected fish showed lethal effects on the parasites within $1 \mathrm{~h}$, whereas prior heat inactivation of complement prevented any parasite killing. Inhibition of the classical pathway by EGTA (ethyleneglycol-tetraacetic acid) treatment of plasma did not prevent the killing. It was shown by immuno-cytochemical assays that C3 bound directly to certain parasite structures (cephalic gland openings, parasite body, hamulus sheath). In contrast, no immunoglobulin binding was detected on the parasites. Lectin-binding assays indicated mannose-rich regions in the cephalic gland openings and lactose derivatives in the hamulus sheath. Galactose derivatives showed a general distribution in the glycocalyx. Thus, the antibody-independent plasma effect on the gyrodactylids are ascribed to the alternative complement pathway, and it is suggested that some carbohydrate epitopes on the parasites are involved in the C 3 activation.
\end{abstract}

KEY WORDS: Rainbow trout Oncorhynchus mykiss - Gyrodactylus · Complement - Immunoglobulin . Glycobiology $\cdot$ Carbohydrate $\cdot$ Lectins

\section{INTRODUCTION}

Numerous investigations have shown that teleosts are able to mount a response against monogenean infections (Jahn \& Kuhn 1932, Nigrelli \& Breder 1934, Paperna 1964, Vladimirov 1971, Lester \& Adams 1974, Scott \& Robinson 1984, Cone \& Cusack 1988, Bakke et al. 1991, Slotved \& Buchmann 1993, Moore et al. 1994, Richards \& Chubb 1996, Buchmann \& Bresciani 1997). The mechanisms involved in these host reactions are still insufficiently elucidated, although a number of host factors have been suggested to affect the survival of the ectoparasites. A weak antibody response against gill monogeneans was shown by Vladimirov (1971) and Buchmann (1993), but cellular reactions are often suggested to have the most influence on gill parasite performance (Paperna 1964, Buchmann 1988). The

\footnotetext{
•E-mail: kurt.buchmann@vetmi.kvl.dk
}

involvement of complement in host reactions was suggested by Vladimirov (1971) and Buchmann \& Bresciani (1997), and recently Harris et al. (1997) demonstrated that serum complement from Salmo salar has a lethal effect on Gyrodactylus salaris. The present study suggests that rainbow trout complement factors are involved in killing (in vitro) of the ectoparasite Gyrodactylus derjavini from this host. In addition, it is indicated by inhibition studies that the alternative pathway is responsible for this effect and that complement factor $\mathrm{C} 3$ binds to and is activated by carbohydrate epitopes (especially mannose-rich structures) on the parasite.

\section{MATERIALS AND METHODS}

Fish. Female rainbow trout (10 to $14 \mathrm{~cm}$ total body length) were purchased from Siglund Fish Production 
(Denmark) and were kept in aerated $200 \mathrm{l}$ laboratory aquaria in freshwater at 11 to $12^{\circ} \mathrm{C}$. One group was kcpt uninfected, whereas another group was infected via cohabitation and kept infected for $2 \mathrm{mo}$.

Living parasites. All experiments with living parasites were conducted at 11 to $12^{\circ} \mathrm{C}$. Living parasites were isolated from rainbow trout fins by allowing the parasites to move from excised fins to the bottoms of small glass-beakers $(4 \mathrm{ml})$ or wells in a microtiter plate (Nunc 96 well immunoplate) filled with tap-water. Thereafter, water, mucus and fin debris were removed and replaced by uncontaminated water several times. Parasites were left untreated for $1 \mathrm{~h}$ whereafter dead parasites were discarded. In the following experiments parasites were incubated in a total volume of $200 \mu \mathrm{l}$ medium. To detect any complement blocking effect of concanavalin A some parasites were preincubated in this unconjugated lectin (10 or $50 \mu \mathrm{g} \mathrm{ml}^{-1}$ ) for $1 \mathrm{~h}$ (Table 1). Specimens of Gyrodactylus derjavini were then exposed to trout plasma diluted 1:1. Plasma samples were used as untreated (native), heat-inactivated or inhibited with $10 \mathrm{mM}$ EGTA-(ethyleneglycoltetraacetic acid)Mg (elimination of calcium ions for inhibition of the classical pathway). Parasites were

Table 1 Survival of Gyrodactylus derjavini in plasma from infected and uninfected rainbow trout incubated for $8 \mathrm{~h}$ in microtiter wells or $3 \mathrm{~h}$ in $4 \mathrm{ml}$ glass beakers

\begin{tabular}{|c|c|c|}
\hline Parasite treatment & $\begin{array}{c}\text { No. of } \\
\text { parasites }\end{array}$ & $\begin{array}{l}\text { Survival } \\
\text { time }\end{array}$ \\
\hline \multicolumn{3}{|l|}{ Microtiter wells, 8 h } \\
\hline \multicolumn{3}{|l|}{ Untreated plasma } \\
\hline Infected host & 5 & $<60 \mathrm{~min}$ \\
\hline Infected host & 5 & $<60 \mathrm{~min}$ \\
\hline Uninfected host & 5 & $<60 \mathrm{~min}$ \\
\hline Uninfected host & 6 & $<60 \mathrm{~min}$ \\
\hline \multicolumn{3}{|l|}{ Heat inactivated plasma } \\
\hline Infected host & 6 & $>8 \mathrm{~h}$ \\
\hline Infected host & 6 & $>8 \mathrm{~h}$ \\
\hline Uninfected host & 5 & $>8 \mathrm{~h}$ \\
\hline Uninfected host & 5 & $>8 \mathrm{~h}$ \\
\hline \multicolumn{3}{|l|}{ Control } \\
\hline Water & 6 & $>8 \mathrm{~h}$ \\
\hline Water & 5 & $>8 \mathrm{~h}$ \\
\hline \multicolumn{3}{|l|}{ Glass beakers, $3 \mathrm{~h}$} \\
\hline \multicolumn{3}{|l|}{ Untreated plasma } \\
\hline Infected host & 7 & $<60 \mathrm{~min}$ \\
\hline Uninfected host & 6 & $<60 \mathrm{~min}$ \\
\hline \multicolumn{3}{|l|}{ Heat inactivated plasma } \\
\hline Infected host & 4 & $>3 \mathrm{~h}$ \\
\hline Uninfected host & 5 & $>3 \mathrm{~h}$ \\
\hline \multicolumn{3}{|l|}{ Plasma + EGTA } \\
\hline Infected host & 5 & $<60 \mathrm{~min}$ \\
\hline Uninfected host & 7 & $<60 \mathrm{~min}$ \\
\hline \multicolumn{3}{|l|}{ Concanavalin $\mathrm{A}(1 \mathrm{~h})$} \\
\hline $10 \mu \mathrm{g} \mathrm{ml}^{-1}$; infected host, untreated plasm & ma 7 & $<60 \mathrm{~min}$ \\
\hline $50 \mu \mathrm{g} \mathrm{ml}{ }^{-1}$; infected host, untreated plasm & $\operatorname{ma} 7$ & $<60$ min \\
\hline \multicolumn{3}{|l|}{ Control } \\
\hline Water & 5 & $>3 \mathrm{~h}$ \\
\hline Water & 5 & $>3 \mathrm{~h}$ \\
\hline
\end{tabular}

exposed according to Table 1, and their survival and motility were followed for 3 or $8 \mathrm{~h}$. Lack of motility and a swollen appearance indicated parasite death.

Plasma. Heparinized blood samples were taken from 5 infected and 5 uninfected rainbow trout by caudal vein puncture. Following centrifugation $(15110 \times g$, $10 \mathrm{~min}$ ) plasma was recovered and stored at $-80^{\circ} \mathrm{C}$ until use. Before experiments, plasma from infected fish was pooled as was plasma from uninfected fish.

Inhibition of complement by heat treatment. Pooled plasma samples were incubated at $44^{\circ} \mathrm{C}$ for 20 min for complement inactivation (Sakai 1992) or left at $4^{\circ} \mathrm{C}$ (untreated).

Inhibition of the classical complement pathway by EGTA addition to plasma. 0.1 M EGTA-Mg solution was added to puoled plasmâ sairiples to a final concontration of $10 \mathrm{mM}$ in the test medium for inhibition of the classical complement pathway (Yano 1992).

Immunocytochemistry. Parasites exposed to plasma for 3 or 8 h were rinsed in phosphate-buffered saline (PBS) and fixed with $4 \%$ neutral formaldehyde for $24 \mathrm{~h}$. After rinsing with PBS ( $1 \mathrm{~h})$ they were blocked ( $1 \mathrm{~h})$ with blocking buffer (PBS containing $2 \%$ bovine serum albumin) and incubated (1 h) with a rabbit serum (diluted $1: 1000$ in blocking buffer) raised against rainbow trout C3 (Jensen \& Koch 1992) or a rabbit serum (diluted 1:1000 in blocking buffer) raised against salmon Ig and cross-reacting with rainbow trout Ig (Buchmann \& Pedersen 1994). Following a wash in PBS with Tween $20(0.05 \%)(3 \times 10 \mathrm{~min})$, parasites were incubated $(1 \mathrm{~h})$ with a peroxidaseconjugated swine antibody raised against rabbit Ig (DAKO P217) (diluted 1:2000). Following a final wash, immunoreactive sites were visualized by reacting with diamino-benzidine-tetrahydrochloride (DAB, DAKO S 3000 ) in the presence of hydrogen peroxide, which produced a brown coloration at binding sites. Parasites were mounted in glycerine-gelatine.

Characterization of carbohydrate epitopes on parasites using lectin-binding assays. Untreated parasites from rainbow trout fins, fixed in $4 \%$ neutral phosphatebuffered formaldehyde, were rinsed in PBS (1 h) and incubated ( $1 \mathrm{~h}$ ) in blocking buffer (PBS with $2 \%$ bovine serum albumin). Thereafter they were incubated ( $1 \mathrm{~h}$ ) with biotinylated lectins $\left(10 \mu \mathrm{g} \mathrm{ml}^{-1}\right)$ in blocking buffer (Table 2). Following lectin binding, parasites were rinsed with PBS containing $0.05 \%$ Tween $20(2 \times 10 \mathrm{~min})$ and incubated ( $60 \mathrm{~min}$ ) with avidine and biotinylated alkaline phosphatase in $0.05 \mathrm{M}$ Tris/ $\mathrm{HCl}, \mathrm{pH} 7.2$ (DAKO K 0376). Following a final rinse with PBS/Tween $(2 \times$ $10 \mathrm{~min}$ ), lectin binding was visualized by reaction with Fast Red TR/Naphthol AS-MX in Tris buffer pH 8.2 (Sigma F-4523). Positive reactions were bright red. Finally, parasites were mounted in glycerine-gelatine and studied under a compound microscope. 
Table 2. Biotinylated lectins used in the binding assay. Major carbohydrate specificity and reactivity with structures on Gyrodactylus derjavini indicated

\begin{tabular}{|c|c|c|c|}
\hline Lectin & Origin & Primary specificity & $\begin{array}{l}\text { Reactivity with } \\
\text { Gyrodactylus derjavini }\end{array}$ \\
\hline Canavalia ensiformis (Concanavalin A) & Sigma C2272 & $\alpha$-D-mannosyl, $\alpha$-D-glucosyl & Cephalic gland duct openings \\
\hline Erythrina corallodendron (ECor A) & Sigma L0893 & $\begin{array}{l}\mathrm{N} \text {-acetyllactosamine, } \\
\mathrm{N} \text {-acetyl-D-galactosamine, lactose, } \\
\text { and D-galactose }\end{array}$ & $\begin{array}{l}\text { Cephalic gland duct openings } \\
\text { and hamulus sheath (weak) }\end{array}$ \\
\hline Helix pomatia & Sigma L6512 & $N$-acetyl- $\alpha$-D-galactosaminyl & General distribution on body \\
\hline Bandeiraea simplicifolia & Sigma L.3759 & $\begin{array}{l}\alpha \text {-D-galactosyl } \\
N \text {-acetyl- } \alpha \text {-D-galactosaminyl }\end{array}$ & General distribution on body \\
\hline Artocarpus integrifolia & Sigma L7775 & $\alpha$-D-galactopyranoside & General distribution on body \\
\hline
\end{tabular}

\section{RESULTS}

\section{Parasite survival}

Parasites exposed to untreated plasma from both infected and uninfected rainbow trout were killed within $1 \mathrm{~h}$, whereas parasites survived well in heatinactivated plasma during the entire study period 3 or $8 \mathrm{~h}$ ). EGTA addition to plasma did not counteract the lethal effect of plasma. Prior incubation of parasites in concanavalin A did not prevent the lethal effect untreated native plasma (Table 1).

\section{Immunocytochemistry}

Immunocytochemical studies of parasites killed in plasma showed binding of $\mathrm{C} 3$ to the cephalic gland openings (Fig. 1), several structures on the body of the parasite (Fig. 2) and the basal part of the hamulus sheath (Fig. 3). Parasites kept in water were completely unstained and parasites kept in heat-inactivated plasma were only extremely weakly stained. No binding of immunoglobulin to the parasites was detected.

\section{Lectin binding}

Canavalia ensiformis lectin (concanavalin A) bound strongly to the cephalic gland openings of Gyrodactylus derjavini, whereas the binding to all other structures in this parasite was very weak to absent (Fig. 4). In contrast, Helix pomatia and Artocarpus integrifolia lectins bound markedly and uniformly to all parts of the parasite surface. Bandeiraea simplicifolia lectins showed a similar uniform but much weaker binding to the parasite. An even weaker general staining was produced with the Erythrina corallodendron lectin.
However, a slightly stronger binding of this lectin was seen in the cephalic gland openings and in one case on the base of the hamulus sheath.

\section{DISCUSSION}

The heat labile lethal effects on Gyrodactylus derjavini of untreated plasma and plasma with EGTA added (from both infected and uninfected fish) indicate that the alternative complement pathway is responsible for the parasite killing observed. This result corresponds to observations on Schistosoma mansoni exposed to host serum, where young schistosomula are extremely sensitive to complement and are killed within a few hours in this medium (Ouiassi et al. 1980. Ruppel et al. 1983, Marikovsky et al. 1990). It could be argued that plasma incubation of ectoparasites is without biological relevance. However, a number of investigations have actually shown that epithelia and mucus of fishes are rich sources of complement. Therefore gyrodactylids do actually live and feed in a complement-rich microenvironment (Buchmann \& Breciani 1998). Further, the immunocytochemical demonstration of rainbow trout $\mathrm{C} 3$ on the cephalic gland openings, parasite body and hamulus sheath of $G$. derjavini suggests that this component is involved in parasite killing. It is actually known to take part in the activation of the lytic complement cascade in rainbow trout (Tomlinson et al. 1993). Moreover, in schistosomula, complement factor $\mathrm{C} 3$ seems to play a crucial role by binding covalently to the parasite tegument (Fishelson 1989. Marikovsky et al. 1990). Several studies have indeed shown immunocytochemical binding of C3 to surface structures on schistosomula (Samuelson \& Caulfield 1986). Complement factor C3 has a central and multifactorial role in the response of host organisms to invading pathogens and, apart from initiating the lytic sequence, $\mathrm{C} 3$ fragments are able to bind to a 


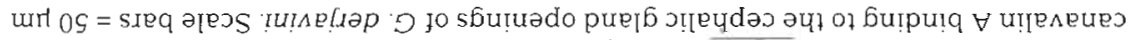

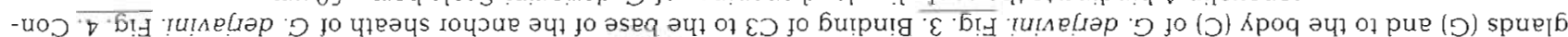

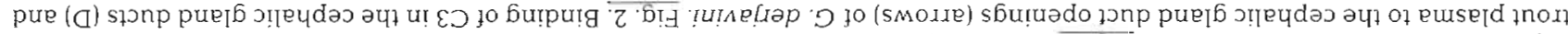

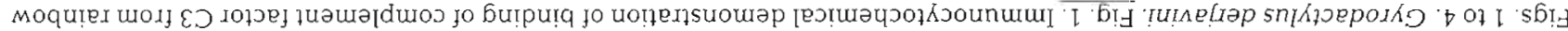
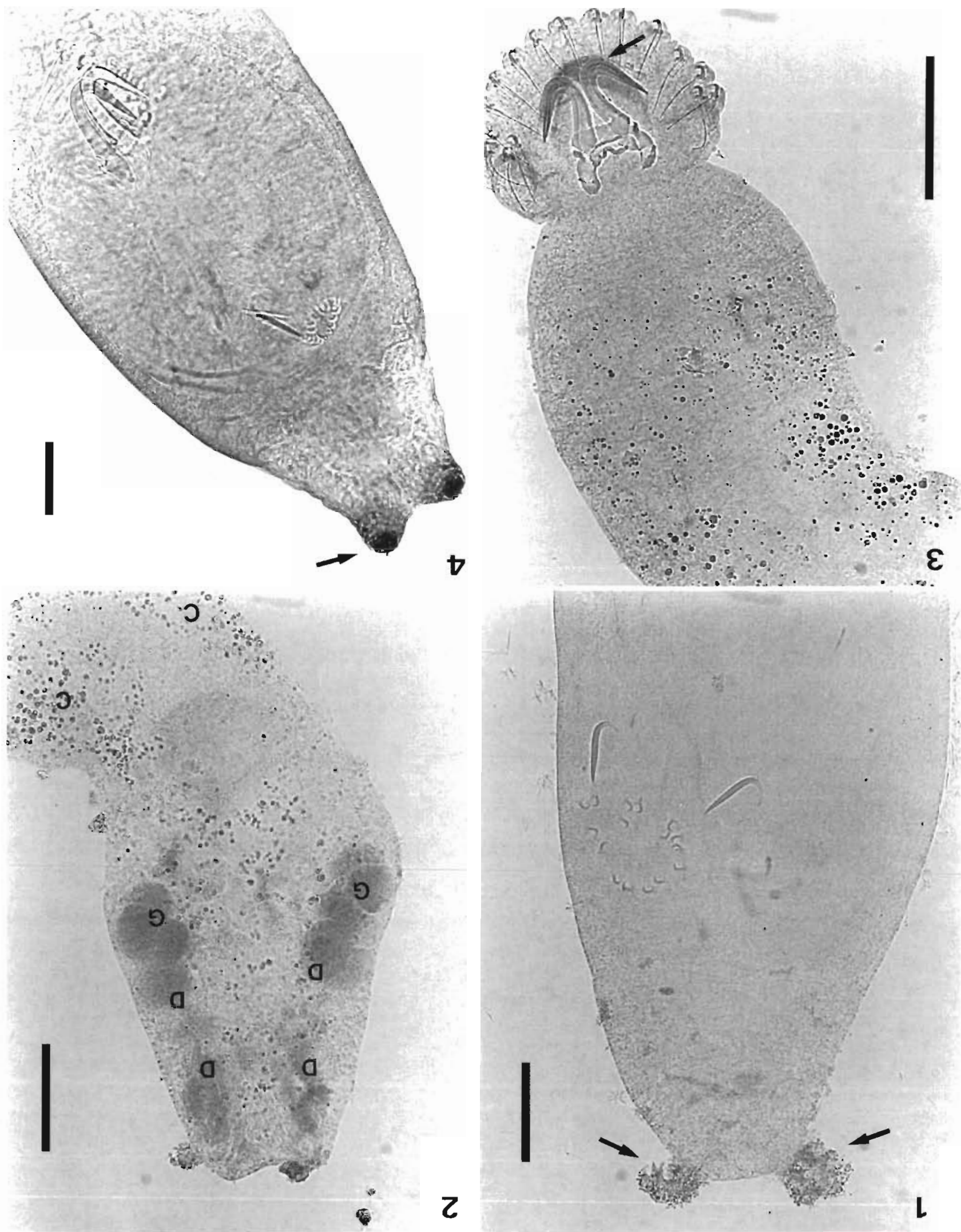
variety of receptors and activate numerous cell types (Lambris 1988). Accordingly, rainbow trout C3 binding to target cells promotes macrophage phagocytosis (Nonaka et al. 1984). That such cellular mechanisms are involved in the response of fishes to the ectoparasitic gyrodactylids in situ cannot be excluded, but the in vitro killing in cell-free media observed in this study probably involves the lytic complement cascade only. The lack of antibody binding to any structures of $G$. derjavini suggests that the response mechanisms in rainbow trout to these monogeneans are independent of immunoglobulins. This also supports the notion that the classical pathway is not involved in the described in vitro killing of $G$. derjavini, which was indicated by the lethal effect of plasma despite EGTA-treatment.

The marked binding of Canavalia ensiformis lectin (concanavalin A) to the cephalic gland openings strongly indicates the presence of a mannose-rich region in this part of Gyrodactylus derjavini. As complement factor $\mathrm{C} 3$ from rainbow trout plasma was found to bind primarily and exactly to these structures, it is suggested that mannose-rich glycoproteins in the cephalic ducts are major activators of the alternative complement pathway in this parasite. Shedding of the glycocalyx in Schistosoma mansoni does actually confer a degree of complement resistance to the parasites (Marikovsky et al. 1990), suggesting that carbohydrates on the parasite surface are important C3 activating epitopes. The general distribution on the parasite body of galactosaminyl (Helix pomatia binding), galactopyranoside (Artocarpus integrifolia binding) and galactosyl (Bandeiraea simplicifolia binding) indicates that galactose derivatives are important components of the tegumental glycocalyx. The weak binding of Erythrina corallodendron lectins to the cephalic gland openings and the hamulus sheath suggest that the few lactose derivatives present in $G$. derjavini are located around these structures. Whether these carbohydrates are involved in C3 activation is unknown but it is notable that both the cephalic gland openings and the hamulus sheath strongly bound C3.

The study also tested whether complement could be prevented from killing the parasite by inhibition of $\mathrm{C} 3$ binding to the mannose-rich regions; however, incubation of parasites with concanavalin A (for a possible competitive inhibition of $\mathrm{C} 3$ attachment to mannoserich regions) prior to exposure to trout plasma did not prevent parasite killing. One possible explanation is that complement binding to structures other than the mannose-rich regions is sufficient to kill the parasite. Alternatively, the fact that $\mathrm{C} 3$ contains concanavalin $\mathrm{A}$ binding sites itself (Alsenz et al. 1992) would enable C3 to attach to the lectins on the cephalic glands. As a result, the lytic pathway would be activated despite prevention of $\mathrm{C} 3$ binding directly to the gland openings.
In conclusion, plasma elements have been shown to have a lethal effect on ectoparasites. These elements seem to be complement related, but further studies should elucidate if various mucus fractions from infected and uninfected fishes have similar effects on Gyrodactylus derjavini.

Acknowledgements. This study was supported by the Danish Agricultural and Veterinary Research Council and the Elisabeth \& Knud Petersen Foundation.

\section{LITERATURE CITED}

Alsenz J, Avila D, Huemer HP, Esparza I, Becherer JD, Kinoshita T, Wang Y, Oppermann S, Lambris JD (1992) Phylogeny of the third component of complement, $\mathrm{C} 3$ : analysis of the conservation of human CR1, CR2, H, and B binding sites, concanavalin A binding sites, and thiolester bond in the $\mathrm{C} 3$ from different species. Dev Comp Immunol 16:63-76

Bakke TA, Jansen PA, Kennedy CR (1991) The host specificity of Gyrodactylus salaris Malmberg (Platyhelminthes, Monogenea): susceptibility of Oncorhynchus mykiss (Walbaum) under experimental conditions. J Fish Biol 39:45-57

Buchmann K (1988) Interactions between the gill parasitic monogeneans Pseudodactylogyrus anguillae and $P$. bini and the fish host Anguilla anguilla. Bull Eur Assoc Fish Pathol 8:98-100

Buchmann K (1993) A note on the humoral immune response of infected Anguilla anguilla against the gill monogenean Pseudodactylogyrus bini. Fish Shellfish Immunol 3:397-399

Buchmann K, Bresciani J (1998) Microenvironment of Gyrodactylus derjavini on rainbow trout Oncorhynchus mykiss: association between mucous cell density in skin and site selection. Parasitol Res 84:17-24

Buchmann K, Pedersen K (1994) A study on teleost phylogeny using specific antisera. J Fish Biol 45:901-903

Cone DK, Cusack R (1988) A study of Gyrodactylus colemanensis Mizelle and Kritsky, 1967 and Gyrodactylus salmonis (Yin \& Sproston, 1948) (Monogenea) parasitizing captive salmonids in Nova Scotia. Can J Zool 66:409-415

Fishelson Z (1989) Complement and parasitic trematodes. Parasitol Today 5:19-25

Harris PD, Soleng A, Bakke TA (1997) Susceptibility of Gyrodactylus salaris to host complement. Bull Scand Soc Parasitol 7:69

Jahn TL, Kuhn LR (1932) The life history of Epibdella melleni MacCallum, 1927, a monogenetic trematode parasitic on marine fishes. Biol Bull (Woods Hole) 62:89-111

Jensen LB, Koch C (1992) Use of monoclonal and polyclonal antibodies to analyse the degradation of rainbow trout C3 in inulin-activated serum. Fish Shellfish Immunol 2: $241-249$

Lambris JD (1988) The multifactorial role of C3, the third component of complement. Immunol Today 9:387-392

Lester RJG, Adams JR (1974) A simple model of a Gyrodactylus population. Int J Parasitol 4:497-506

Marikovsky M, Parizade M, Arnon R, Fishelson Z (1990) Complement regulation on the surface of cultured schistasomula and adult worms of Schistosoma mansoni. Eur J Immunol 20:221-227

Moore MM, Kaattari SL, Olson RE (1994) Biologically active factors against the monogenetic trematode Gyrodactylus 
stellatus in the serum and mucus of infected juvenile English soles. J Aquat Anim Health 6:93-100

Nigrelli RF, Breder CM (1934) The susceptibility and immunity of certain fishes to Epibdella melleni, a monogenetic trematode. J Parasitol 20:259-269

Nonaka M, Iwaki M, Nakai C, Nozaki M, Kaidoh T, Nonaka M. Natsuume-Sakai S, Takahashi M (1984) Purification of a major serum protein of rainbow trout (Salmo gairdneri) homologous to the third component of mammalian complement. J Biol Chem 259:6327-6333

Ouaissi MA, Santoro F, Capron A (1980) Schistosoma mansoni: ultrastructural damages due to complement on schistosonula in vitro. Exp Parasitol 50:74-82

Paperna I (1964) Host reaction to infestation of carp with Dactylogyrus vastator Nybelin, 1924 (Monogenea). Bamidgeh 16:129-141

Richards GR, Chubb JC (1996) Host response to initial and challenge infections, following treatment, of Gyrodactylus builatarudis and $G$. iurnubili (Monugenea) on the guppy (Poecilia reticulata). Parasitol Res 82:242-247

Ruppel A, Rother U, Vongerichten H, Diesfeld HJ (1983) Schistosoma mansoni: complement activation in human and rodent sera by living parasites of various develop-

Editorial responsibility: Wolfgang Körting,

Hannover, Germany mental stages. Parasitology 87:75-86

Sakai DK (1992) Repertoire of complement in immunological defense mechanisms of fish. Annu Rev Fish Dis 2:223-247

Samuelsun JC, Caulfield JP (1986) Ccrcarial glycocalyx of Schistosoma mansoni activates human complement. Infect Immun 51:181-186

Scott ME, Robinson MA (1984) Challenge infections of Gyrodactylus bullatarudis (Monogenea) on guppies, Poecilia reticulata (Peters), following treatment. J Fish Biol 24: $581-586$

Slotved HC, Buchmann K (1993) Acquired resistance of the eel, Anguilla anguilla L., to challenge infections with gill monogeneans. J Fish Dis 16:585-591

Tomlinson S, Stanley KK, Esser AF (1993) Domain structure, functional activity, and polymerization of trout complement protein C9. Dev Comp Immunol 17:67-76

Vladimirov VL (1971) The immunity of fishes in the case of dactylogyrosis. Parasitologiya 5:51-58 (English translation: Riverdale 1971, Parasitology 1:58-68)

Yano T (1992) Assays of hemolytic complement activity. In: Stolen JS, Fletcher TC, Anderson DP, Kaattari SL, Rowley AF (eds) Techniques in fish immunology. SOS Publications, Fairhaven

Submitted: September 29, 1997; Accepted: December 29, 1997 Proofs received from author(s): February 16, 1998 